\title{
О.Л. Чурашева
}

\section{СЕЛЬСКАЯ БИБЛИОТЕКА КАК ПРОСТРАНСТВО СОЦИАЛИЗАЦИИ ЛИЧНОСТИ}

\section{Рецензия на книгу «Социальная работа сельских библиотек Томской области: направления, возможности, вклад в развитие села (2000-2010-е гг.)»}

Социальная работа сельских библиотек Томской области: направления, возможности, вклад в развитие села (2000-2010-е гг.) / К.А. Кузоро, А.А. Ляпкова, Е.А. Масяйкина, А.И. Дегтярева; под ред. К.А. Кузоро. Томск : Изд-во Том. ун-та, 2019. 116 с.

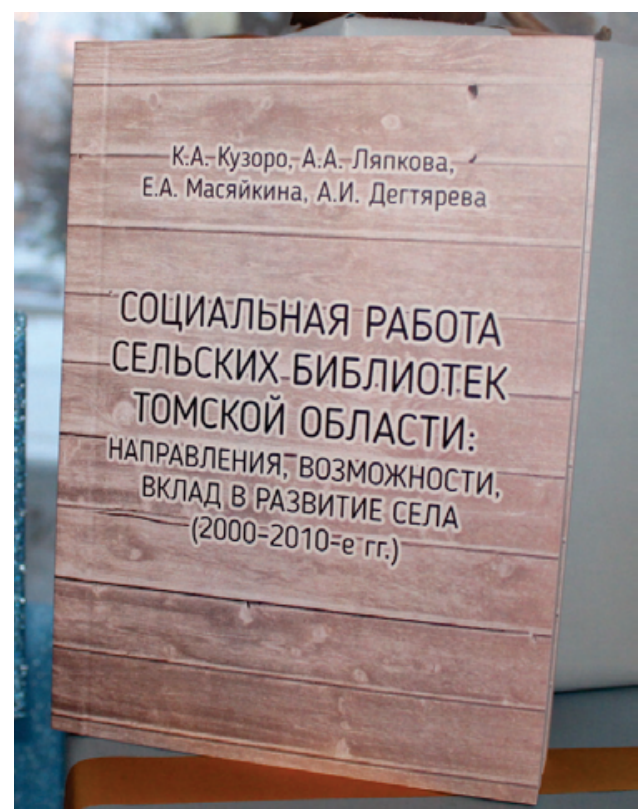

Сельская библиотека в России традиционно являлась центром культуры, образования и общения. Эта тенденция прослеживается еще со времен организации земских сельских народных библиотек и усиливается в 20-30-е, а затем в 60-70-е гг. XX в.

$\mathrm{B}$ начале XXI в. перед сельской библиотекой как социальным институтом стоит значительно более сложная задача. В условиях массового оттока трудоспособного сельского населения в города, в условиях сокращения на селе количества организаций культурной и образовательной сферы и как следствие в 
условиях сужения и обеднения социокультурного и информационного пространства сельских жителей сельская библиотека, как справедливо указывают авторы монографии, «остается практически единственным культурным центром, способствующим общению и сближению жителей села, объединению различных по социальному статусу слоев населения, способным к созданию безбарьерной информационной среды для тех категорий населения, которым необходима дополнительная социальная поддержка» (С. 4).

Таким образом, актуальность и социальная значимость тематики монографии не вызывает сомнений. Она обусловлена все возрастающей ролью сельской библиотеки как института социализации и творческого развития личности, а также центра для эффективной коммуникации и сближения различных социальных групп.

Структура монографии тщательно продумана и отражает исследовательские интересы авторов.

В первом разделе К.А. Кузоро дается общая характеристика направлений социальной работы библиотек Томской области. Автором выделяется шесть ключевых направлений: работа с читателями с ограниченными возможностями здоровья, работа с трудными подростками, профориентационная работа, формирование правовой и информационной культуры, культурно-досуговая деятельность, экологическое просвещение.

Второй раздел монографии посвящен характеристике организации обслуживания читателей с ограниченными возможностями здоровья в сельских библиотеках Томской области. Описаны разнообразные формы библиотечноинформационной обслуживания (консультации, курсы компьютерной грамотности, книгоношество, коллективный абонемент, культурно-досуговые мероприятия, клубы по интересам и др.), используемые для работы с различными категориями читателей-инвалидов. Необходимо подчеркнуть, что система этих форм обслуживания вполне воспроизводима и, таким образом, может служить образцом, ориентиром для деятельности других библиотек в этом направлении.

Третья часть монографии посвящена такому важному направлению деятельности библиотеки, как работа с семьей. Авторы (А.А. Ляпкова, А.И. Дегтярева, К.А. Кузоро) рассматривают эту деятельность многоаспектно, однако наибольший акцент делают на следующих направлениях: продвижение семейного чтения, работа с приемными семьями, помощь в творческом развитии и социализации трудных подростков, организация клубов и кружков по интересам для детей из многодетных и малообеспеченных семей и т.д.

Следующий раздел монографии посвящен роли сельских библиотек в воспитании здорового образа жизни. Здесь справедливо отмечается, что «результативное приобщение населения к здоровому образу жизни возможно только при взаимодействии учреждений здравоохранения, образования, культуры, социальных служб, средств массовой информации» (С. 45). Традиционно деятельность библиотек в этом направлении ограничивалась зачастую лишь выставочной работой. Тем больший практический интерес представляет опыт библиотек Томской области, где к вопросу популяризации здорового образа жизни подходят комплексно, используя различные формы работы, как традиционные, так и новые: выставки, обзоры статей из периодических изданий, спортивные эстафеты, подвижные игры, викторины, индивидуальные консультации с медицинскими работниками, дискуссии, видеолекции, клубы по интересам. 
С проблемой пропаганды здорового образа жизни тесно связана деятельность библиотеки по развитию экологической культуры читателей, чему и посвящен следующий раздел монографии. Формирование экологического сознания граждан является приоритетной задачей государственной политики РФ, в связи с чем экологическое просвещение читателей крайне актуально. Необходимо подчеркнуть, что данная деятельность в Томской области осуществляется в рамках разработки и реализации библиотеками социокультурных проектов регионального масштаба, что, безусловно, придает этой работе системность и комплексность.

Последние разделы коллективной монографии посвящены характеристике двух взаимосвязанных направлений работы сельских библиотек - краеведческой и музейной деятельности. В настоящее время краеведение, являясь одним из важнейших направлений работы любой общедоступной библиотеки, постоянно обогащается инновационными формами практической деятельности и обретает новые черты. В связи с этим глубокий анализ опыта сельских библиотек в области краеведческой деятельности, представленный в монографии, является, на взгляд рецензента, ценным информационным ресурсом, способным обогатить библиотечную практику. Интерес представляет и опыт организации краеведческих экспозиций в ряде сельских библиотек Томской области.

Следует отметить, что исследования авторов монографии выполнено на богатой источниковой базе, что придает работе исчерпывающую полноту, репрезентативность и многоаспектность. Так, были использованы следующие группы источников информации: информационно-аналитические отчеты библиотек районов Томской области и сводные аналитические обзоры ТОУНБ им. А.С. Пушкина; материалы районной периодической печати, посвященные деятельности сельских библиотек; интернет-публикации, раскрывающие опыт социальной работы российских и зарубежных публичных библиотек; материалы сайтов межпоселенческих библиотечно-информационных систем и центральных районных библиотек Томской области; база данных «Профессионалам» ТОУНБ им. А.С. Пушкина; материалы групп, организованных и поддерживаемых библиотеками в социальных сетях.

Завершая рецензию, следует приветствовать появление нового монографического исследования, посвященного социальным функциям сельских библиотек в новом столетии. Данная работа займет достойное место в фонде отечественных профессиональных изданий, будет интересна теоретикам и практикам в области библиотечного дела, а также будет способствовать трансляции уникального опыта сельских библиотек Томской области в национальном масштабе. Очевидно также, что систематизация опыта социальной работы сельских библиотек позволит не только совершенствовать практическую деятельность по данному направлению, но и будет способствовать формированию научно-методической базы такой деятельности. tion).

Olga L. Churasheva, St. Petersburg State Institute of Culture (St. Petersburg, Russian Federa-

E-mail: Olgatchurasheva@yandex.ru

Vestnik Tomskogo gosudarstvennogo universiteta. Kul'turologiya i iskusstvovedeniye - Tomsk State University Journal of Cultural Studies and Art History, 2019, 33, pp. 313-315.

DOI: $10.17223 / 22220836 / 33 / 28$

RURAL LIBRARY AS A SOCIALIZATION SPACE 